\title{
Social comparison processes and adults' judgments of children's weight and intentions to control children's weight
}

\author{
Jenny Reichert, ${ }^{1}$ Monica K. Miller ${ }^{2}$ \\ ${ }^{1}$ Psychology, Rocky Mountain College, Billings, MT; ${ }^{2}$ Criminal Justice, University of Nevada, Reno, \\ NV, USA
}

\begin{abstract}
To combat rising rates of childhood obesity in the U.S. requires helping parents recognize when their child is overweight or obese. However, parents' accuracy might be affected by social comparisons, in which parents compare their child to other overweight children, and rationalize that their child is 'normal' weight, and therefore, healthy. The aim of the study was to assess
\end{abstract}

Correspondence: Jenny Reichert, Ph.D., Assistant Professor, Psychology, Rocky Mountain College, Billings, MT 59102, USA.

Tel.: +1.406.6571074.

E-mail: jenny.reichert@rocky.edu

Key words: Children's health, vicarious social comparison, childhood obesity, recognition of overweight and obesity, parents' judgments of children's weight.

Contributions: JR completed design of the survey, data collection, data analysis, and report writing as part of a dissertation project under the direct supervision of MM, who provided valuable feedback throughout the process.

Conflict of interest: The authors declare no potential conflict of interest.

Funding: This study was funded in part by the Bilinski Educational Foundation Dissertation Year Fellowship granted at the University of Nevada, Reno. The Foundation had no input on study design, the collection, analysis, or interpretation of the data, in the writing of the report, or the decision to submit it for publication.

Ethics approval and consent to participate: This project was approved by the Institutional Review Board (IRB) of the University of Nevada, Reno, in 2013 under protocol number 2013S047. Data from this project have been presented at the annual meeting of the Western Social Sciences Association in 2016.

Consent for publication: Consent has been received prior to publication.

Availability of data and materials: All data and materials are available within the text.

Received for publication: 5 January.

Revision received: 25 June 2020.

Accepted for publication: 25 June 2020.

This work is licensed under a Creative Commons AttributionNonCommercial 4.0 International License (CC BY-NC 4.0).

${ }^{C}$ Copyright: the Author(s), 2020

Licensee PAGEPress, Italy

Health Psychology Research 2020; 8:8797

doi:10.4081/hpr.2020.8797 whether a photograph of a fictional child impacts a parent's judgment of their own child's weight. A nationwide sample of parents $(n=517)$ of children ages 2-12 provided their child's height and weight, viewed a photograph of an underweight (upward comparison), normal weight (control) or overweight (downward comparison) child, and judged the health of both. Parents inaccurately judged the downward comparison compared to the control and upward comparisons. Further, parents were less accurate in judging their child's weight when given an upward comparison compared to a control. Intentions to control their children's weight were unaffected.

\section{Introduction}

Rising rates of childhood obesity have transformed children's health from a public concern to a major social issue (Centers for Disease Control and Prevention [CDC], 2017; Robinson, 2008; Skinner, Perrin, \& Skelton, 2016). The solution to childhood overweight and obesity seems manageable through decreased caloric intake and increased physical activity. However, failure to properly address the issue has less to do with reluctance or avoidance of the issue as previously thought. Rather, many parents are unable to recognize that their own children are overweight or obese (Eckstein et al., 2006; Huang, Donohue, Becerra, \& Xu, 2009; Lundahl, Kidwell, \& Nelson, 2014; Vanhala, KeinanenKiukaanniemi, Kaikkonen, Laitinen, \& Korpelainen, 2011; West et al., 2008).

Rising rates of obesity might have resulted in adjusted attitudes toward what is considered a healthy body weight (Wang, Beydoun, Liang, Caballero, \& Kumanyika, 2008), such that what was considered overweight historically is now considered normal. This combined with the lack of knowledge about the prevalence of obesity that would allow parents to make objective judgments about their children's weight have made it difficult for parents to identify their children as overweight or obese.

There is a need for parents to recognize their children's overweight and obesity in order for parents to change their own and their children's behavior to address it. Parents influence their children's weight by providing food and modeling healthy behavior. Parents who perceive their child as overweight describe themselves as readier to implement lifestyle changes to help their child lose weight, in contrast to parents who do not recognize their child's weight issue (Rhee, DeLago, Arscott-Mills, Mehta, \& Davis, 2005). Children with weight issues are most successful in losing weight when their parents are actively engaged in the process (Golan \& Crow, 2004; Rhee, et al., 2016; Spear, et al., 2007; Wadden, Stunkard, \& Rich, 1990; Wrotniak, Epstein, Paluch, \& Roemmich, 2005).

Social psychology as a field can help reduce childhood obesity 
by identifying the factors that prevent recognition of overweight and obesity, including comparisons parents might make between their child and other children when deciding whether their child is overweight or obese.

\section{Introduction to social comparison}

Individuals require knowledge about the social world for effective, efficient decision-making. Objective judgments of one's own abilities can be difficult to make in many situations. According to Social Comparison Theory (SCT) (Festinger, 1954; Gerber, Wheeler, \& Suls, 2018), one simple way to gather information about the self to guide behavior and to build or maintain self-esteem is by comparing the self to a target other (Flores \& Miller, 2004). Comparisons between the self and others, whether intentional or not, are pervasive in social contexts. These processes involve automatic, spontaneous comparisons during which individuals consider their own attributes and successes in comparison to those of target others (Festinger, 1954), which provides enough information to reduce uncertainties and guide everyday decisionmaking (Marsh et al., 2010). Individuals might use their relative standing compared to those around them in order to make selfevaluations, even when objective means are available to do so (Wood, 1989); many times, when the situation calls for it, individuals then adjust their behavior according to the conclusions drawn (Marsh et al., 2010).

One of the most widely studied areas in social comparison research involves body image appraisals, specifically concerning weight status, because information about body size is so easily accessible (Faith, Leone, \& Allison, 1997). The consequences of these comparisons will depend on a number of factors, including the comparison target and the direction of the comparison.

\section{Consequences of comparisons}

Comparisons between the self and others may lead to changed affect, perceptions, and behavior. Social comparison information also influences perceptions of risk for those facing physical health issues (Lipkus \& Klein, 2006), and could lead them to process information about health issues differently. These perceptual changes could also lead to behaviors or lifestyle changes that increases objective risk of the health issue if the individual believes erroneously that their risk is especially low. It should follow then that providing parents with a social comparison target would distort their perceptions of their child's weight and their behavioral intentions to control their child's weight, especially if their accuracy is compromised. Behavioral intentions reflect motivation to perform certain behaviors or the effort one is prepared to exert in order to achieve a desired outcome (Azjen, 1991). The researchers focused on behavioral intentions as a dependent variable in this study rather than behavior both as a time- and cost-saving measure and because Webb and Sheeran (2006) found that in some cases, behavioral intention does predict behavior change; specifically, they found that medium-to-large change in behavioral intention leads to a small-tomedium change in behavior. In this study, the accuracy of parents' judgments was assessed using a 'deviation score' which measures the distance between their child's actual weight status and their perception of their child's weight status.

\section{Direction of comparison}

Affective and behavioral consequences of comparisons differ according to how the target performs in a domain relevant to the individual's sense of self-worth (Alicke, LoSchiavo, Zerbst, \& Zhang,1997). An upward social comparison occurs when a target outperforms the individual or possesses some attribute that threatens the individual's self-esteem. This comparison creates negative affect and presumably strengthens behavioral intentions. In contrast, a downward social comparison occurs when an individual compares herself to a target whose performance or attributes are considered less than those of the individual. This comparison creates positive affect and might not strengthen behavioral intentions. The current study tested whether the type of comparison affects participants' judgments about the weight of their own child and their intentions for a healthier lifestyle for their child. When presented with an upward comparison, parents may underestimate their child's weight status in order their child matches the child in the photograph, who is at an 'ideal' weight, and therefore, healthy. This is done in order to maintain the parent's self-esteem, which may be threatened at the thought that their child weighs more (i.e., is less healthy) than the child in the photograph. It may also be that parents will overestimate the weight of their child, though historically, this is uncommon (Baughcum, Chamberlain, Deeks, Powers, \& Whitaker, 2000; Jackson, Strauss, Lee, \& Hunter, 1990; Scholten's et al., 2007).

\section{Vicarious social comparisons}

Most research on social comparisons has focused on how comparisons affect evaluations of the self or intentions for the self (Gilbert, Giesler, \& Morris, 1995; Zell \& Alicke, 2010). This body of research has neglected to examine vicarious social comparison, or how comparisons with targets lead to evaluative judgments on behalf of another, and how these comparisons influence behavioral intentions for the other. In this case, vicarious social comparison specifically refers to the evaluative judgments of parents on behalf of their children.

Research on vicarious cognitive dissonance supports the idea that parents will make vicarious social comparisons on behalf of their child and that these comparisons will lead to behavioral outcomes. Vicarious cognitive dissonance occurs when one observes an important in-group member engage in inconsistent behavior (Norton, Monin, Cooper, \& Hogg, 2003). Vicarious cognitive dissonance arises as the observer imagines the discomfort of the actor member engaging in the inconsistent behavior, and reacts as if he were an in-group member trying to justify his own behavior: his attitudes change to be more supportive of the inconsistent behavior. This experience is moderated by a number of factors (Norton et al., 2003) including the connection between the observer and the actor. Indeed, such experiences are more likely to arise when the actor is connected or liked (Heider, 1958), seen as very similar (Krebs, 1975), or been assimilated into a social identity that defines both parties as members of the same group (Terry \& Hogg, 1996). Presumably, parents perceive their child as connected, liked, or similar to themselves, and their social identities as parents rely solely on their children. Essentially, the effects of cognitive dissonance (e.g., attitude change) can result even when the dissonance is not experienced directly. In the same way, the effects of social comparison (e.g., behavioral intentions) might also result even when the comparison is not experienced directly.

Research on vicarious cognitive dissonance does not address how vicarious experiences affect intended or actual behavior for the individual or for the other. Nor does this research indicate whether these effects would extend from a direct comparison with the self to an indirect comparison with someone for whom the individual felt responsible. It stands to reason that parents who felt responsible for their children would be invested in their children's health, and as a result, would feel inclined to change their or the child's behavior to improve the child's health when threatened by a social comparison. 


\section{Overview of current study}

Social comparison processes could explain parents' failure to recognize overweight and obesity in their own children. Because information about body size is easily accessible and in recent years body size has been increasing steadily, parents might make comparisons between their children and the typical American child, who is considerably larger now than in the past. As a result, parents might simply fail to recognize that their own child is overweight or obese.

The aim of this study was to address parents' lack of recognition of overweight and obesity in children by assessing whether a photograph of a fictional child impacts a parent's judgment of their own child's weight. Researchers gave parents either an upward or downward comparison (photos of children who either weighed less or more than their own child) and then asked parents to classify their own child's health using terms like 'Healthy weight', 'Moderately overweight', etc. A figure of a slightly underweight individual is considered ideal by children, adolescents, and adults (Collins, 1990; Davies \& Furnham, 1986); presumably, even if the parent has a child that is very underweight, a comparison to a slightly underweight child should be seen as an upward comparison. In contrast, the parent of a very overweight child might still see a very overweight target (the fictional child in the photograph) as a downward comparison, because they might not believe that their own child is very overweight (Eckstein, et al., 2006; Huang et al., 2009).

The hypothesis is as follows: parents given an upward comparison (i.e., a photo of a children that is slightly underweight, seen as 'ideal') are predicted to respond with a less accurate judgment of their child's weight status and report stronger intent to put their child on a weight-loss diet and increase their child's physical exercise than those given a downward comparison (i.e., a photo of a child who is severely overweight).

\section{Materials and Methods}

\section{Participants}

All participants self-identified as parents ( $n=867$, hereafter referred to as 'participants'). Participants ranged in age from $18-$ 95 years $(M=34.3, M d n=33)$ and $71.7 \%$ were female. Most $(78.5 \%)$ were White, $42.7 \%$ were normal weight and $52.8 \%$ were either overweight or obese. When judging the weight status of their own children, $80.4 \%$ underestimated their child's weight status (i.e., believed their child belonged to a lower weight status than they actually did) and $19.6 \%$ overestimated the child's weight status (i.e., believed their child belonged to a higher weight status that they actually did). Only 517 participants provided information about their own child. Of their children, $55.8 \%$ were male, $42.7 \%$ were normal weight while $40.2 \%$ were overweight or obese according to our BMI calculations, and they ranged in age from $2-12$ years $(M$ $=5.78, M d n=5$ ).

\section{Procedure and design}

Participants completed the 45-60-minute survey online through Amazon Mechanical Turk (MTurk) in exchange for \$.50. MTurk was designed to as a crowdsourcing site for businesses ('Requesters') to pay 'workers' for labor; since its inception it's been widely used by social science researchers as a research participant pool (Martini, Springer, Clark, \& Richardson, 2019; Springer, Martini, Lindsey, \& Vezich, 2016). Most research suggests that
MTurk workers are similar demographically to other internet-based samples (Ipeirotis, 2009) and more representative of the general U.S. population compared to the typical college student sample used by psychology researchers (Buhrmester, Kwang, \& Gosling, 2011). Participants completed a pre-screening questionnaire that included questions about their child's gender and age. Responses determined which of a series of SurveyMonkey sites the participants were directed to, each set up to match the gender age of the child they described during pre-screening. Within these sets, there was a random photograph generator that either displayed i) the upward social comparison (the slightly underweight child), ii) the downward social comparison (the severely overweight child) or iii) a control comparison (normal weight). This photograph was followed by perception questions for the photograph and questions regarding their own child's weight.

\section{Manipulated photograph}

Social comparison targets were provided by a photograph of a real child provided in the survey. Photographs of children were manipulated by the researchers to create a total of 18 photographs (gender: male or female; age: 2-5 years, 6-9 years, 10-12 years) at various weight stages (slightly underweight, healthy weight, severely overweight). The various weight stages were based on sketched silhouettes of children developed by Collins (1990). The manipulated photograph provided a direction of comparison, used as an independent variable in the model.

\section{Questionnaire}

\section{Demographic information}

Participants provided basic demographic information including age, gender, height, and weight. Height and weight were used to calculate parent BMI, used as a covariate in the model.

\section{Information about own child}

Parents were instructed to choose the child in their household between the ages of 2-12 with the most recent past birthday, and provided that child's gender, height, age, and weight. Height and weight were used to calculate child BMI, used as a covariate in the model along with child age and child gender.

\section{Dependent variables}

The purpose of the study was to test for the existence of vicarious social comparison on the following perception and intent variables.

\section{Perception of child's weight}

Parents were asked to subjectively rate their child's weight status on a scale from 0-100 (with a rating of 0 signifying 'severely underweight' and a rating of 100 signifying "severely overweight"). This rating alone would not serve as the dependent variable, but rather deviation from actual weight status, to measure the participants' 'misperception' of the child's weight. Calculation of deviation scores is described below.

\section{Intentions for own child - weight-loss diet}

Parents indicated whether they intend to put their child on a weight-loss diet in the immediate future using a 5-point Likert-type scale: 'Yes,' 'Probably,' 'Undecided,' 'Probably not,' 'No.' 


\section{Intentions for own child-exercise}

Parents indicated whether they intend to increase their child's level of activity using a 5-point Likert-type scale: 'Yes,' 'Probably,' 'Undecided,' 'Probably not,' 'No.'

\section{Results}

\section{Manipulation check question}

A manipulation check question testing whether participants correctly understood the direction of comparison were unsuccessful. Parents given downward comparisons did not rate the fictional child as weighing significantly more than did parents given an upward comparison $(p s>.05)$. Rather, all children were rated on average as 'normal weight'. When parents were asked to rate the child's health in terms of weight using a scale that placed 'normal weight' at a score of 50, mean weights for the severely overweight child, slightly underweight child, and normal weight child were 46.14 , 45.90 , and 43.26, respectively.

\section{Calculation of Covariates, Dependent Variables}

\section{Parent BMI calculation, status assignment}

Participants' BMI scores were calculated using the height and weight provided by participants and the established formula: Height in Inches $2 /$ Weight in lbs x 703 (Centers for Disease Control and Prevention, 2017). Participants' BMI scores reflect amount of body fat, with higher scores indicating higher body fat. BMI categorizations for adults according to the Centers for Disease Control and Prevention are as follows: $<18.5=$ Underweight, 18.5 $-24.9=$ Normal weight, $25-29.9=$ Overweight, and $\leq 30.0=$ Obese (Centers for Disease Control and Prevention, 2017).

\section{Child BMI calculation, status assignment}

Children's BMI scores were calculated using the children's heights and weight provided by parents and the same CDC formula stated above. BMI categorizations for children depend on gender and age. All children were assigned a categorization. These were used to test the accuracy of parents' judgments of their children's weight. Although there was a chance that parents reported inaccurate estimates of their children's weight and height, historically, these estimates have been very accurate (Baughcum et al., 2000; Maynard, Galuska, Blanck, \& Serdula, 2003).

\section{Dependent variable}

\section{Deviation scores}

This will measure the parents' 'misperception' of the child's weight. It is a subjective measure, rather than an objective measure of difference of weight in pounds. Past research shows that although parents' reports of their children's weights in pounds were very accurate, their perceptions of their children's health (healthy versus unhealthy) based on their weight were not (Baughcum et al., 2000; Maynard et al., 2003); in this way, a parent could know objectively exactly how much their child weighs in pounds, but still not perceive their child as overweight or unhealthy. Parents must perceive their child as overweight in order to perceive a health risk.

During the survey, parents were asked to subjectively rate the weight of their actual child on a scale from 0-100 (with a rating of 0 signifying 'severely underweight' and a rating of 100 signifying 'severely overweight'). The actual child's BMI was calculated (using the parents' reports of their child's height and weight, which has been shown to be fairly accurate in the past; Dammann, Smith, $\&$ Richards, 2011). The children were then assigned corresponding scores on the 100-point scale, i.e., children who were classified as 'normal weight' according to their BMI scores were assigned a score of 50. Deviation scores were then calculated using difference between the perceived weight status of their child and their child's actual weight status. Parents' scores on the Deviation measure can range from $0-100$, with higher scores reflecting greater deviation from the actual weight status, i.e., parents with greater deviation scores were less accurate judges of their child's weight status. For example, if the parent's child has a BMI in the $90^{\text {th }}$ percentile or greater (meaning the child weighs more than $90 \%$ of other children the same age, height and gender), then this child will be labeled as 'severely overweight' and would be assigned a weight status score of 100 for the study. When asked to rate the child's health, if the parent labels the child 'normal weight' (which would be a score of 50 ), that parent's deviation score will be a 50. If the parent instead labels the child as moderately overweight (scored as 75), the parent's deviation score would be 25. Parents were allowed to give any numerical label between $0-100$, and their deviation scores were calculated according to the child's actual weight score. Larger deviations were treated as greater misperception of their child's weight.

\section{Model Building}

The independent variable was the direction of comparison (upward, downward, control) and dependent variables included parents' deviation scores, intentions to put their own child on a weight-loss diet, and intentions to increase their own child's exercise. Covariates were chosen as factors with statistically significant influence on parents' accuracy (Abbott, Lee, Stubbs, \& Davies. 2010; Doolen, Alpert, \& Miller, 2009; Mamun, McDermott, O'Callaghan, Najman, \& William 2008). Covariates include parent BMI, child age, child gender and child BMI. The model is statistically significant overall (Wilk's $\lambda=.745, F(18,396)=6.80$ $p<.0001)$.

\section{Overall model}

All covariates, with the exception of parent BMI, were significant predictors in the overall model: child BMI (Wilk's $\lambda=.904, F(3,394)=13.88, p<.001)$, child age (Wilk's $\lambda=.917, F(3$, $394)=11.82, p=.001)$ and child gender (Wilk's $\lambda=.976, F(3$, $394)=3.959, p<.05)$. Parents reported stronger intentions for weightloss diet and exercise and higher deviation scores as child BMI increased; intentions for weight-loss diet and exercise were also stronger for those with male children compared to those with female children. Child age was positively related to intentions but negatively related to deviation scores.

\section{Diet, exercise, deviation scores}

To assess each predictor's contribution to the dependent variables, a multivariate regression was conducted using multiply imputed data with the same independent and dependent variables. 
The model was significant for all three dependent variables $(p s<.001)$ and accounted for $7.4 \%$ of the variance in intentions to put their own child on a weight-loss diet, $6.1 \%$ of the variance in intentions to increase their own child's exercise, and $14.9 \%$ of the variance in the absolute value of parents' deviation scores. A main effect for direction of comparison emerged for parents' deviation scores: parents given an upward comparison $(M=28.13)$ scored significantly higher on deviation from their actual child's weight status than those given a control comparison $(M=11.58)(p<.001)$. There was no main effect for direction of comparison for intent for weight-loss diet or intent for exercise $(p>.05)$.

\section{Discussion}

Childhood obesity rates are increasing in the United States, due in part to parents' failure to recognize their own child's overweight or obesity. This study was conducted to address this failed recognition by testing for vicarious social comparisons for parents, who were thought to judge their child's weight status based on comparisons they make between their children and other children. However, results reveal that vicarious social comparison as it was conceptualized in this project only significantly predicted deviation scores, but not intentions for weight-loss diet and exercise. It could be that their intentions were not predicted by direction of comparison because they were unaware of how inaccurate their judgments were of their child's weight, as most underestimated their child's weight. Parents are unlikely to indicate that they plan to take steps to reduce their child's weight if they believe that their child is normal or healthy weight.

Interestingly, several of the demographic variables entered into the model as covariates did significantly predict behavioral intentions. Parents reported stronger intentions to control their child's weight as their child's BMI and age both increased. As child BMI increases, their weight becomes more visible; in these cases, parents may be more likely to conceive of their child's weight as a health issue and report stronger behavioral intentions to control their child's weight. Additionally, parents are more likely to see overweight in very young children as a product of 'baby fat' and less likely to consider it a health issue; rather, mothers in particular see an overweight infant as a healthy baby (Baughcum, Burklow, Deeks, Powers, \& Whitaker, 1998). They assume their children will 'grow out of it' naturally without their help (Baughcum et al., 1998), and as a result they report weaker behavioral intentions for younger children than they do older children. Lastly, parents report stronger overall intentions for their male rather than female children. This result seems to contradict most past research, which shows that parents are more likely to recognize their overweight female children as overweight compared to their overweight male children (Baughcum et al., 2000) and warrants further investigation.

The manipulation check was unsuccessful in that those given a downward comparison did not rate the child as significantly heavier than those given an upward comparison. However, this result is similar to past research (Maynard et al., 2003). Further, this lends support to the basic premise of the study, suggesting that parents in general are unable to recognize an obese child as significantly heavier than a slightly underweight child. Nonetheless, the comparison manipulation did significantly predict parents' deviation scores (i.e., difference between their child's actual weight status and their perceived weight status). Parents given an upward comparison had higher deviation scores than parents given a control comparison, when controlling for parent BMI, child BMI, child age, and child gender. In other words, even if parents cannot tell specifically that a child is slightly underweight (or weighs less in comparison to an overweight child), the child's body size still affects the parent's judgment. Having a comparison target that was closer to an ideal weight than their own child distorted parents' judgments of their children's weight, regardless of the parent's BMI, the child's BMI, age or gender. In contrast, when asked to compare their child to a control child of normal weight, their judgments were significantly more accurate. According to past research on social comparisons, parents' self-esteem may be threatened by the idea that their children were not of the 'ideal weight', and therefore they are bad parents. They attempt to maintain self-esteem by underestimating their child's weight to fall in line with the image of the 'ideal' (underweight) child, resulting in larger deviation scores overall. In contrast, when presented with a photograph of a normal weight or overweight child, parents are comfortable reporting accurate weight judgments for their own children because they experience no threat to self-esteem and do not need to engage in those maintenance behaviors.

\section{Implications}

This study was designed to contribute to the literature on social comparison theory, specifically to determine whether parents make vicarious social comparisons, in which comparing their child to other children affects their judgments and behavioral intentions. Results show that the effect for vicarious social comparison was weak, and only influenced deviation scores. However, the study of vicarious social comparisons has only begun. Future research will assess whether vicarious social comparisons operate in everyday life for parents with their children or even for other interactive pairs (e.g., romantic relationships) and how they affect perceptions, behaviors, and emotions.

In the area of health research, oftentimes approaches to combating widespread epidemics like childhood obesity are designed to address only a certain subset of needs or behaviors that contribute to the rise in obesity rates. These approaches might neglect to consider how environmental and demographic differences influence how families perceive obesity. The number of parents in this study who incorrectly judged their child's weight status shows that there is a need to help parents identify children at healthy and unhealthy weights for children in order to make objective judgments about their own child's needs, rather than relying on subjective estimates of children's body sizes.

\section{Limitations and future directions}

There are several limitations to the study. New measures for vicarious social comparison were developed for the study with no past evidence that they would operate in the desired way. Indeed, there is no past evidence that vicarious social comparisons even exist, and these measures produced only one significant effect (i.e., deviation scores). In this way, it is difficult to know whether these measures are valid, because the existence of vicarious social comparisons is questionable. Future studies using evaluations others than children's body size will reveal whether they truly affect cognition and behavior.

Sampling issues include using Amazon Mechanical Turk as a platform for recruiting participants. Although using MTurk has some benefit over Internet samples and university student samples (Buhrmester et al., 2011), it still might not tap into part of the population of interest that recruiting participants manually would. Every worker registered on MTurk necessarily has access to an Internet connection, and this does not exactly represent the entire 
U.S. population. It likely under-represents parents of lower income families, who might struggle with overweight and obesity even more than middle class families (Singh, Siahpush, \& Kogan, 2010). Stratified sampling using targeted community recruitment may be more successful in reaching these populations for future studies.

Next, the study used photographs of White children. This was done primarily to save time and conserve resources, but it could alienate minority participants who cannot realistically compare their child to a White child. This would render the comparison ineffective. Future studies on vicarious social comparison could focus on matching comparison children to the parents' children exactly (including age, race, gender, and even other class markers like clothing worn) to assure that a comparison is made.

Lastly, deviation scores were calculated to show how distorted participants' perceptions were when judging the weight of the child in the photograph and their own child. Only absolute values of participants' deviation scores were used in analyses because the focus of this study was distortion in general, such that larger scores represent greater distortion (without taking into account the direction of the distortion). Presumably, participants would underestimate the child's weight status, and when judging children's weights, this is largely the case (Baughcum et al., 2000; Jackson et al., 1990; Scholten's et al., 2007). In general, very few overestimate the weight status of a child (only $19.6 \%$ of this sample). That said, to overestimate a child's weight status is likely influenced by different factors than is underestimating a child's weight status, and future analyses would need to account for this distinction.

\section{Conclusions}

Obesity rates in the United States have risen dramatically in the past decades, doubling for children and adolescents alone (Centers for Disease Control and Prevention, 2011). A number of factors contribute to obesity in children, including adults' inability to accurately judge children's weight. Many parents simply fail to recognize that their child has a weight problem, leaving the child at risk for a number of significant health issues. Results show that vicarious social comparisons do affect judgments of weight in children but do not affect intentions to control children's weight, likely because parents are unaware of how inaccurate their judgments are. Current campaigns to reduce obesity tend to focus on actions parents and educators can take to reduce children's caloric intake and increase their physical activity. However, results from this study suggest that in order to be effective, these efforts need to begin with educating parents to recognize obesity first, before providing methods to reduce it. Unless parents recognize that their child's health is at risk, they are likely going to ignore current campaigns.

\section{References}

Abbott, R.A., Lee, A.J., Stubbs, C.O., \& Davies, P.S. (2010). Accuracy of weight status perception in contemporary Australian children and adolescents. Journal of Pediatric Child Health, 46(6), 343-348. doi: 10.1111/j.1440-1754.2010.01719.

Alicke, M.D., LoSchiavo, F.M., Zerbst, J., \& Zhang, S. (1997). The person who outperforms me is a genius: Maintaining perceived competence in upward social comparison. Journal of Personality and Social Psychology, 73, 781-789. doi:10.1037/0022-3514.73.4.781.
Azjen, I. (1991). The theory of planned behavior. Organizational Behavior and Human Decision Processes, 50, 179-211. doi: 10.1016/0749-5978(91)90020-T.

Baughcum, A.E., Burklow, K.A., Deeks, C.M., Powers, S.W., \& Whitaker, R.C. (1998). Maternal feeding practices and childhood obesity: A focus group study of low-income mothers. Archives of Pediatrics and Adolescent Medicine, 152(1), 10101014. doi: 10.1001/archpedi.152.10.1010.

Baughcum, A.E., Chamberlin, L.A., Deeks, C.M., Powers, S.W., \& Whitaker, R.C. (2000). Maternal perceptions of overweight preschool children. Pediatrics, 106(6), 1380-1386. doi: 10.1542/peds.106.6.1380.

Buhrmester, M., Kwang, T., \& Gosling, S.D. (2011). Amazon's Mechanical Turk: A new source of inexpensive, yet high-quality data? Perspectives on Psychological Science, 6, 3-5. doi: 10.1177/1745691610393980.

Cameron, L., Rutland, A., Brown, R., \& Douch, R. (2006). Changing children's intergroup attitudes toward refugees: Testing different models of extended contact. Child Development, 77(5), 1208-1219. doi: 10.1111/j.14678624.2006.00929.x.

Centers for Disease Control and Prevention (CDC). (2017). Prevalence of obesity among adults and youth: United States, 2015-2016. Retrieved May 4, 2020 from https://www.cdc.gov/nchs/data/databriefs/db288.pdf.

Collins, M.E. (1990). Body figure perceptions and preferences among preadolescent children. International Journal of Eating Disorders, 10(2), 199-208. doi: 10.1002/1098108X(199103)10:2.

Davies, E., \& Furnham, A. (1986). The dieting and body shape concerns of adolescent females. Journal of Child Psychology and Psychiatry, 27, 417-428. doi: 10.1111/j.14697610.1986.tb01843.x.

Doolen, J., Alpert, P.T., \& Miller, S.K. (2009) Parental disconnect between perceived and actual weight status of children: A metasynthesis of the current research. Journal of the American Academy of Nurse Practitioners, 21, 160-166. doi: 10.1111/j.1745-7599.2008.00382.x.

Eckstein, K.C., Mikhail, L.M., Ariza, A.J., Thomson, J.S., Millard, S.C., \& Binns, H.J. (2006). Parents' perceptions of their child's weight and health. Pediatrics, 117(3), 681 - 690. doi: 10.1371/journal.pone.0059923.

Faith, M.S., Leone, M., \& Allison, D.B. (1997). The effects of selfgenerated comparison targets, BMI, and social comparison tendencies on body image appraisal. Eating Disorders: The Journal of Treatment and Prevention, 5, 34-46. doi: $10.1080 / 10640269708249216$.

Festinger, L. (1954). A theory of social comparison processes. Human Relations, 7, 117-140. doi: 10.1177/001872675400700202.

Flores, D. \& Miller, M.K. (2004). Social comparison. In Ritzer, G. \& Ryan, J.M. (Eds.), The Concise Encyclopedia of Sociology. Oxford: Blackwell.

Gerber, J.P., Wheeler, L., \& Suls, J. (2018). A social comparison theory meta-analysis $60+$ years on. Psychological Bulletin, 144(2), 177-197. doi: 10.1037/bul0000127.

Gilbert, D.T., Giesler, R.B., \& Morris, K.A. (1995). When comparisons arise. Journal of Personality and Social Psychology, 69(2), 227-236. doi: 10.1037/h0042291.

Golan, M. \& Crow, S. (2004). Targeting parents as the exclusive agents of change in the treatment of childhood obesity: Long term results. Obesity Research, 12, 357-361. doi: 10.1038/oby.2004.45. 
Heider, F. (1958). The psychology of interpersonal relations. New York: Wiley.

Huang, J.S., Donohue, M., Becerra, K., \& Xu, R. (2009). Relationship between parents' and childrens' weight perceptions results of a survey. ICAN: Infant, Child, \& Adolescent Nutrition, 1(1),15-20. doi: 10.1177/1941406408329218.

Ipeirotis, P.G. (2009, March 16). Turker demographics vs. internet demographics. A Computer Scientist in a Business School. https://www.behind-the-enemy-lines.com/2009/03/turkerdemographics-vs-internet.html.

Jackson, J., Strauss, C.C., Lee, A.A., \& Hunter, K. (1990). Parent's accuracy in estimating child weight status. Addictive Behaviors, 15(1), 65-68. doi: 10.1016/0306-4603(90)90007-K

Krebs, D. (1975). Empathy and altruism. Journal of Personality and Social Psychology, 32, 1134-1146. doi: 10.1037/00223514.32.6.113.

Lipkus, I.M. \& Klein, W.M. (2006). Effects of communicating social comparison information on risk perceptions for colorectal cancer. Journal of Health Communication, 11(4), 391-407. doi:10.1080/10810730600671870.

Lundahl, A., Kidwel, K.M., \& Nelson, T.D. (2014). Parental underestimates of child weight: A meta-analysis. Pediatrics, 133(3), 689-703. doi: 10.1542/peds.2013-2690.

Mamun, A.A., McDermott, B.M., O'Callaghan, M.J., Najman, J.M., \& William, G.M. (2008). Predictors of maternal misclassification of their offspring's weight status: A longitudinal study. Internal Journal of Obesity, 32, 48-54. doi: 10.1038/sj.ijo.0803757.

Marsh, H.W., Seaton, M., Kuyper, H., Dumas, F., Huguet, P., Regner, I., Buunk, A.P., Monteil, J., \& Gibbons, F.X. (2010). Phantom behavioral assimilation effect: Systematic biased in social comparison choice studies. Journal of Personality, 78, 671-710. doi: 10.1111/j.1467-6494.2010.00630.x.

Martini, P.J., Springer, V.A., Clark, J.D., \& Richardson, J.T. (2019) Studying Muslim identity online in post-9/11 America: Results and implications for accessing stigmatized minority groups. In A. Possamai-Inesdy \& A. Nixon (Eds.), The digital social: Religion and belief (pp. 67-88). De Gruyter.

Maynard, L.M., Galuska, D.A., Blanck, H.M., \& Serdula, M.K. (2003). Maternal perceptions of weight status of children. Pediatrics, $111, \quad 1226-1231$. doi: 10.1111/j.13652214.2012.01380.x.

Norton, M.I., Monin, B., Cooper, J., \& Hogg, M.A. (2003). Vicarious dissonance: Attitudes change from the inconsistency of others. Journal of Personality and Social Psychology, 85(1), 4-62. doi: 10.1037/0022-3514.85.1.47. 47.

Rhee, K.E., DeLago, C.W., Arscott-Mills, T., Mehta, S.D., \& Davis, R.K. (2005). Factors associated with parental readiness to make changes for overweight children. Pediatrics, 116, 94-101. doi: 10.1542/peds.2004-2479.

Rhee, K.E., Jelalian, E., Boutelle, K., Dickstein, S., Seifer, R., \& Wing, R. (2016). Warm parenting associated with decreasing or stable child BMI during treatment. Childhood Obesity, 12(2), 94-102. doi: 10.1089/chi.2015.0127.

Robinson, T.N. (2008). Treating pediatric obesity: Generating the evidence. Archives of Pediatric and Adolescent Medicine 16(2), 1191-1192. doi: 10.1001/archpedi.162.12.1191.

Rochman, B. (2011, July 13). Should parents lose custody of their extremely obese kids? Time. Retrieved from http://healthland.time.com/2011/07/13/should-parents-losecustody-of-their-very-obese-kids/.

Scholtens, S., Brunekreef, B., Visscher, T. L. S., Smit, H. A., Kerkhof, M., Jongste, J. C., Gerritsen, J., \& Wijga, A. H. (2006).
Reported versus measured body weight and height of 4-yearold children and the prevalence of overweight. European Journal of Public Health, 17(4), 369-374. doi: 10.1093/eurpub/ck1253.

Silverstein, B., Peterson, B., \& Perdue, L. (1986). Some correlates of the thin standard of bodily attractiveness for women. International Journal of Eating Disorders 5, 895-905. doi: 10.1002/1098-108X(198607)5:5<895::AID-

EAT2260050510>3.0.CO;2-W.

Singh, G.K., Siahpush, M., \& Kogan, M.D. (2010). Disparities in children's exposure to environmental tobacco smoke in the United States. Pediatrics, 126(1), 4-13. doi: 10.1542/peds.20092744.

Skinner, A.C., Perrin, E.M., \& Skelton, J.A. (2016). Prevalence of obesity and severe obesity in US children, 1999-2014. Obesity, 24(5), 1116-1123. doi: 10.1002/oby.21497.

Spear, B.A., Barlow, S.E., Ervin, C., Ludwig, D.S., Saelens, B.E., Schetzina, K.E., \& Taveras, E.M. (2007). Recommendations for treatment of child and adolescent overweight and obesity. Pediatrics, 120(4), S254-S288. doi: 10.1542/peds.2007-2329F.

Springer, V.A., Martini, P.J., Lindsey, S.C., \& Vezich, I.S. (2016). Practice-based considerations for using multi-stage survey design to reach special populations on Amazon's Mechanical Turk. Survey Practice, 9(5). doi: 10.29115/SP-2016-0029.

Terry, D.J. \& Hogg, M.A. (1996). Group norms and the attitudebehavior relationship: A role for group identification. Personality and Social Psychology Bulletin, 22, 776-793. doi: 10.1037/1089-2699.2.1.48

Wadden, T.A., Stunkard A.J., \& Rich L. (1990). Obesity in black adolescent girls: a controlled clinical trial of treatment by diet, behavior modification and parental support. Pediatrics, 85, 345-352.

Wardle, J. \& Beales, S. (1986). Restraint, body image and food attitudes in children from 12 to 18 years. Appetite, 7, 209-217. doi: 10.1016/S0195-6663(86)80026-5.

Wang, U., Baydoun, M., Liang, L., Caballero, B., \& Kumanuyika, S. (2008). Will all Americans become overweight or obese? Estimating the progression and cost of the US obesity epidemic. Obesity, 16(10), 2323-2330. doi: 10.1038/oby.2008.351.

Webb, T.L. \& Sheeran, P. (2006). Does changing behavioral intentions engender behavior change? A meta-analysis of the experimental evidence. Psychological Bulletin, 132(2), 249268. doi: 10.1037/0033-2909.

West, D.S., Raczynski, J.M., Phillips, M.M., Bursac, Z., Gauss, C.H., \& Montgomery, B.E. (2008). Parental recognition of overweight in school-age children. Obesity, 16(3), 630-636. doi: 10.1038/oby.2007.108.

Wright, S.C., Aron, A., McLaughlin-Volpe, T., \& Ropp, S.A. (1997). The extended contact effect: Knowledge of cross-group friendships and prejudice. Journal of Personality and Social Psychology, 73, 73 - 90. doi: 10.1037/h0021234.

Wood, J.V. (1989). Theory and research concerning social comparisons of personal attributes. Psychological Bulletin, 106, 231-248. doi: 10.1037/0033-2909.106.2.231.

Wrotniak, B.H., Epstein L.H., Paluch R.A., \& Roemmich J.N. (2005). The relationship between parent and child self-reported adherence and weight loss. Obesity Research, 13, 1089-1096. doi: 10.1038/oby.2005.127.

Zell, E. \& Alicke, M.D. (2010). Comparisons over time: Temporal trajectories, social comparison, and self-evaluation. European Journal of Social Psychology, 40, 375-382. doi: 10.1002/ejsp.737. 